\title{
Intraventricular Primary Central Nervous System Lymphoma Mimicking Ventriculitis
}

\author{
Tetsuya Hirato, Kenichi Komatsu, Namiko Nishida and Sadayuki Matsumoto
}

Key words: primary central nervous system lymphoma, intraventricular lymphoma, ventriculitis

(Intern Med 60: 1797-1798, 2021)

(DOI: 10.2169/internalmedicine.6174-20)
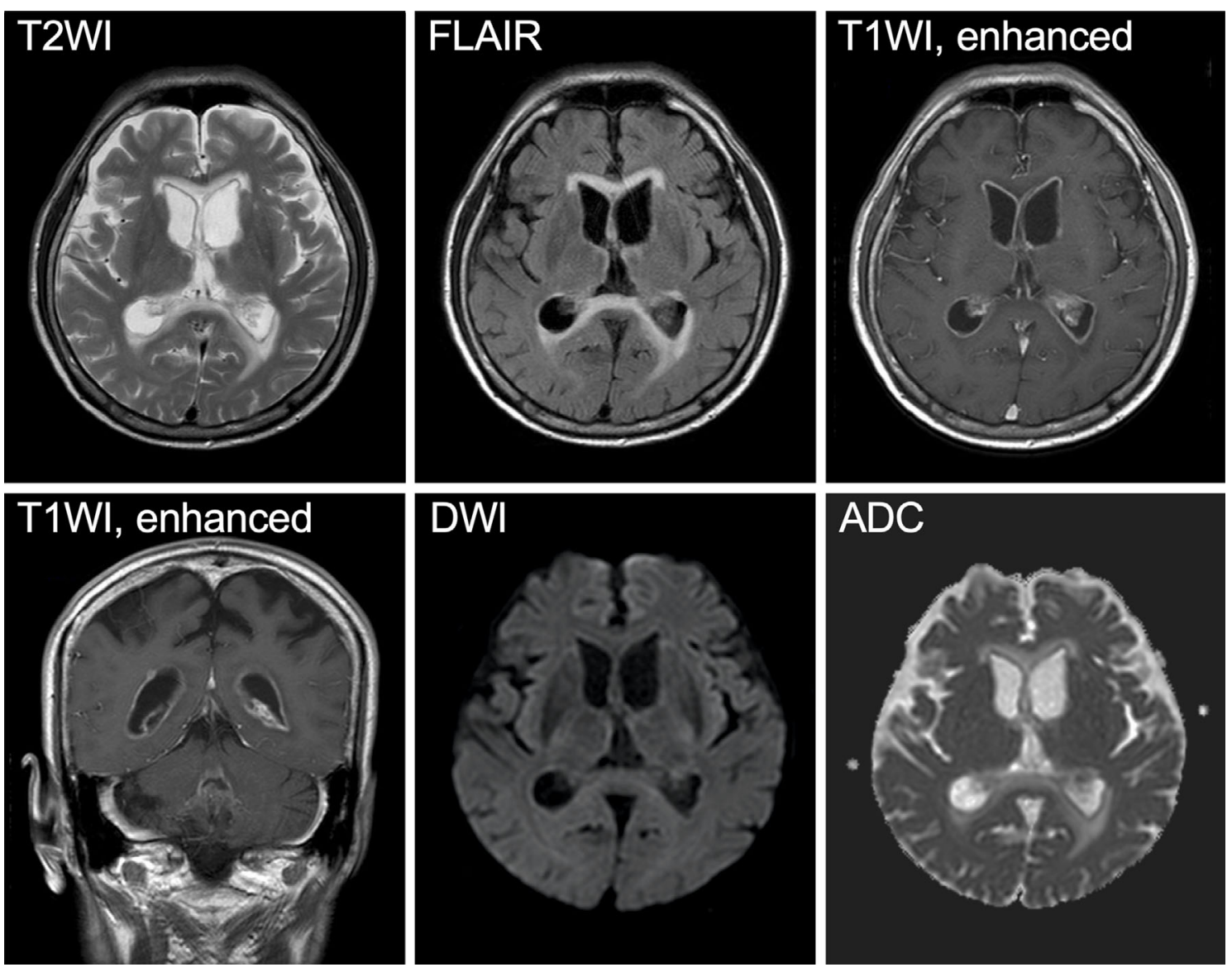

Picture 1.

A 76-year-old man taking prednisolone for organized pneumonia presented with fatigue and consciousness disturbance progressing over a week. He had no fever or headache. He could follow only simple commands and showed weakness of the right upper extremity and bilateral Babinski signs. His neck was supple. T2-weighted and fluidattenuated inversion recovery imaging showed ventricular enlargement with periventricular edema, and gadoliniumenhanced imaging showed thin linear enhancement along the ventricular walls, characteristic findings of infectious ventriculitis (1). There was no diffusion restriction (Picture 1). Chest-abdominal computed tomography findings were unremarkable. Blood tests showed hyponatremia but a normal Creactive protein level. Treponemal antibodies were negative. 

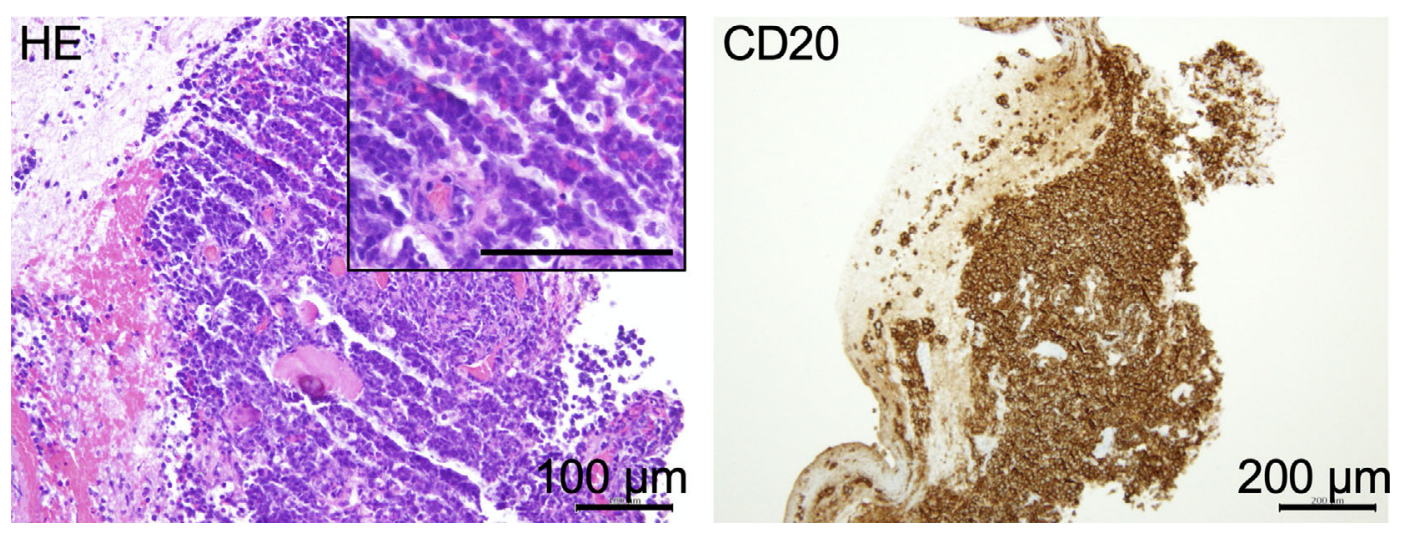

Picture 2.

An interferon-gamma release assay for tuberculosis had been negative one year earlier, and the patient's inactive lifestyle was not suggestive of new infection of tuberculosis. Cerebrospinal fluid (CSF) showed mild pleocytosis $(25 / \mu \mathrm{L})$ and a normal glucose level. A CSF smear examination and cryptococcal antigen findings were negative. Further data were not available at that time due to a long holiday period. His clinical course and laboratory data were more suggestive of malignancy than infection; therefore, a neuroendoscopic biopsy was performed. Hematoxylin-eosin staining of the ventricular walls showed infiltration of large lymphocytes with a high nuclear-cytoplasmic ratio and immunopositivity for CD20 (Picture 2), revealing diffuse large B cell lymphoma. Isolated intraventricular lymphoma is rare, but it is an important differential diagnosis of ventriculitis (2). The CSF findings differ from those of ventriculitis and can be the key for the diagnosis.
The authors state that they have no Conflict of Interest (COI).

\section{Acknowledgement}

The authors thank Dr. Yoshiaki Yuba (Department of Pathology, Kitano Hospital, The Tazuke Kofukai Medical Research Institute) for the pathological analysis.

\section{References}

1. Smirniotopoulos JG, Murphy FM, Rushing EJ, Rees JH, Schroeder JW. Patterns of contrast enhancement in the brain and meninges. Radiographics 27: 525-551, 2007.

2. Yamamoto S, Nagano S, Shibata S, Kunieda T, Imai Y, Kohara N. Primary central nervous system lymphoma mimicking ventriculitis. Rinsho Shinkeigaku (Clin Neurol) 53: 831-834, 2013 (in Japanese, Abstract in English).

The Internal Medicine is an Open Access journal distributed under the Creative Commons Attribution-NonCommercial-NoDerivatives 4.0 International License. To view the details of this license, please visit (https://creativecommons.org/licenses/ by-nc-nd/4.0/).

(C) 2021 The Japanese Society of Internal Medicine Intern Med 60: 1797-1798, 2021 